\title{
SINERGIA
}

REVISTA DO INSTITUTO DE CIÊNCIAS ECONÔMICAS, ADMINISTRATIVAS E CONTÁBEIS (ICEAC)

\section{POR TRÁS DOS COSMÉTICOS: ANÁLISE DA (IN)FORMALIDADE DA PROFISSÃO DE MAQUIADOR NO MUNICÍPIO DE PONTE NOVA - MINAS GERAIS}

\author{
CARINA MONTEIRO TAVARES \\ KAMILA GABRIELA JACOB* \\ JÉSSICA NATÁLIA DA SILVA MARTINS ${ }^{* * *}$
}

\begin{abstract}
RESUMO
Este estudo teve como objetivo apresentar o profissional do ramo de maquiagem na cidade de Ponte Nova, Minas Gerais, e a sua relação com o mercado (in)formal no município. Para tanto, realizou-se um estudo descritivo de caráter qualitativo e quantitativo, aplicando-se questionários semiestruturados a 23 profissionais de Maquiagem. Dentre os principais resultados, foi possível observar que, ao se tornar MEl, o Maquiador adquire segurança jurídica e benefícios amparados por lei, mas nem todos os profissionais envolvidos buscaram a formalidade no exercício da profissão. O estudo avança com relação à literatura existente ao discutir uma profissão ainda pouco estudada e ao associar a discussão do profissional Maquiador ao empreendedor. Além disso, denota a importância da formalização no mercado de trabalho, esclarecendo as principais vantagens para que aqueles que ainda atuam na informalidade possam obter certa segurança em exercer a profissão.
\end{abstract}

Palavras-Chave: Maquiagem, Microempreendedor Individual, Formalidade, Informalidade.

\section{ABSTRACT}

This study aimed to present the professional in the makeup field in the city of Ponte Nova, Minas Gerais, and their relationship with the (in)formal market in the city. Therefore, a descriptive study of qualitative and quantitative character was carried out, applying semi-structured questionnaires to 23 makeup professionals. Among the main results, it was possible to observe that when becoming MEI, the makeup artist acquires legal security and benefits supported by law, but not all professionals involved sought formality in the exercise of the profession. The study advances in relation to the existing literature by discussing a profession that is still little studied and by associating the discussion of the professional makeup artist with the entrepreneur. Furthermore, it denotes the importance of formalization in the labor market, clarifying the main advantages so that those who still work informally can obtain certain security in exercising the profession.

Keywords: Makeup, Individual Micro Entrepreneur, Formality, Informality.

Recebido em: 15-06-2021 Aceito em: 10-11-2021

\section{INTRODUÇÃO}

O cenário econômico brasileiro que, antes da pandemia, apresentava indícios de uma economia debilitada - com taxa média de crescimento nos últimos três anos próxima a 1\%, contas públicas fragilizadas e famílias endividadas, constata, no período pandêmico, impacto significativo no número de pessoas sem emprego (CARVALHO et al, 2021). De acordo com dados estatísticos divulgados pelo Instituto Brasileiro de Geografia e Estatística (IBGE), a taxa de desocupação do trimestre móvel de abril a junho de 2021 era de $14,1 \%$, o que correspondia a 14,4 milhões de pessoas em busca de trabalho (IBGE,2021).

A taxa de desemprego elevada fez com que governantes, com viés neoliberal, pregassem o afrouxamento da legislação trabalhista e a diminuição da intervenção estatal no mercado de trabalho, sob a justificativa de que tais medidas aqueceriam a economia, sendo as únicas capazes de gerar novos postos de trabalho. Todo esse movimento acarretou em significativas alterações legislativas, principalmente, as nomeadas leis da terceirização (BRASIL, 2017) e a Reforma Trabalhista (BRASIL, 2017), ainda no governo do então presidente Michel Temer.

Contudo, tais medidas, apontadas como solução para o problema do desemprego, acarretaram na precarização das relações de trabalho, colocando o trabalhador, presumidamente hipossuficiente, em situação de maior dependência em relação aos seus empregadores e, ainda assim, não produziram os efeitos

\footnotetext{
Bacharelanda em Ciências Contábeis pela Faculdade Dinâmica do Vale do Piranga (FADIP).

"Mestre em Economia pela Universidade Federal de Viçosa (UFV). Docente da Faculdade Dinâmica do Vale do Piranga (FADIP). Email: kamila.g.jacob@gmail.com
} 
prometidos, pois não gerou mais empregos como esperado (FAGUNDEZ, 2019). Segundo os dados apresentados pelo Cadastro Geral de Empregados e Desempregados (Caged), apresentados pelo Sindicato das Empresas de Serviços Contábeis e das Empresas de Assessoramento, Perícias, Informações e Pesquisas no Estado do Paraná - SESCAP (2019), no período compreendido entre novembro de 2017 e setembro de 2020 , foram gerados 286,5 mil postos de trabalho, valor inferior à previsão do governo anterior que tinha como objetivo gerar mais de 6 milhões de empregos no país.

Desde então, a frustrada procura pela entrada no mercado de trabalho fez com que parte da população tivesse que "empreender" como alternativa para obtenção de renda e o consequente sustento da família. Além disso, a fim de evitar a volatilidade das relações de trabalho e os baixos salários, muitos sonham em "ser o próprio patrão", dando ouvidos à vontade de crescer que cada pessoa carrega dentro de si. Entretanto, não basta só ter vontade. Além de conhecimento sobre o negócio que pretende iniciar, para conseguir vencer em um mercado competitivo, é necessário ter muito discernimento (LIMA; NASSIF, 2017).

De forma concomitante e como oportunidade de negócio, percebe-se que tanto mulheres quanto homens têm aumentado a preocupação com os cuidados pessoais, beleza e estética, buscando o corpo e o rosto perfeitos, e isso está se tornando a formação da identidade das pessoas (FÉLIX PARREIRA et al., 2019). Dessa forma, buscou-se abordar esse assunto, que é tido como relevante pela sociedade.

Considerando a evolução do mercado econômico do país, o ramo da maquiagem é um setor que diariamente vem se expandindo conforme os padrões de beleza surgidos. Contudo, ainda são escassas as estratégicas e bens para que a profissão de maquiador se mantenha ativa no mercado (MENDES, 2019).

A aquisição de produtos de beleza continua avançando no Brasil, tornando-o o terceiro país no mercado mundial de cosméticos, ficando atrás apenas dos Estados Unidos e o Japão. Em levantamento feito pela Associação Brasileira de Redes de Farmácias e Drogarias (ABRAFARMA) entre janeiro e março de 2019, o setor varejista de cosméticos movimentou $\mathrm{R} \$ 4,7$ bilhões, e esse valor refere-se a um crescimento de $10,64 \%$, correspondente ao mesmo período do ano de 2018 (CORREIO BRAZILIENSE, 2019).

Dessa forma, infere-se que o profissional de maquiagem, assim como qualquer outro, para manter-se no mercado, deve se destacar por algum motivo e, para isso, deve utilizar de estratégias para o enfrentamento da concorrência, seja por meio de uma marca diferenciada, seja sua forma de atender aos clientes. Não obstante, acredita-se que grande parte dos qualificados ainda se encontra em situação informal.

Mesmo com a existência da Lei Complementar № 128, de 19 de dezembro de 2008, que visa propor uma alternativa frente ao regime tributário de Microempresa (ME) e Empresa de Pequeno Porte (EPP), com a exposição de uma nova forma jurídica (Microempreendedor Individual - MEI), acredita-se que muitos empreendedores ainda não se atentaram aos benefícios da formalidade. Isso se deve, dentre outros fatores, pela falta de conhecimento, incentivo e medo da longevidade do negócio (OLIVEIRA et al., 2017).

Nesse sentido, observou-se que alguns estudos buscaram traçar o perfil do empreendedorismo, como Silva e Guimarães (2018) no segmento da beleza e da estética e Lemos e Borges (2018) na análise do Empreendedorismo nos Centros de Estética, mas nenhum deles analisou especificamente a profissão de maquiador, fazendo com que a profissão esteja sem estudos atuais na área. Dessa forma, esse estudo possui as questões de pesquisa: Qual é o perfil do profissional de maquiagem do município de Ponte Nova - Minas Gerais? Qual é a percepção sobre os benefícios da formalização destes profissionais?

Como objetivos esse estudo buscou descrever o perfil do profissional de maquiagem do município de Ponte Nova - Minas Gerais e analisar a sua percepção sobre os benefícios da formalização. A escolha pela cidade de Ponte Nova se dá por conveniência para os pesquisadores, principalmente no momento de Pandemia da COVID - 19, uma vez que se tornou possível ter acesso à maioria dos profissionais de expressão do segmento.

O presente trabalho apresenta relevância empírica e teórica. No primeiro caso, enfoca em um ramo específico de atividade, qual seja a prestação de serviços de profissionais de maquiagem e busca explicar a atuação de pequenos empreendedores nesse segmento em Ponte Nova e apresenta as prováveis razões para que alguns optem pela informalidade e outros recorram à formalização, trazendo os possíveis caminhos a serem seguidos por estes profissionais para que consigam melhores condições de vida e trabalho. Ademais, o estudo apresenta contribuições teóricas no que tange à caracterização do profissional analisado, uma vez que é pouco estudado na literatura. Além disso, instiga a discussão sobre o empreendedorismo em período de crise, oferecendo indicações para novos estudos sobre o tema.

Além desta introdução, este estudo está estruturado em outras quatro seções. A seção seguinte apresenta discussões acerca dos temas intervenientes para a compreensão da atuação do profissional maquiador. Posteriormente, são apresentados os passos percorridos para a realização da pesquisa. Adiante, são expostas as discussões e resultados sobre a atuação dos profissionais pesquisados que atuam no município de Ponte Nova - MG, e por fim, são apresentadas as considerações finais. 


\section{REFERENCIAL TEÓRICO}

Para melhor esclarecer sobre a temática, torna-se necessário apresentar o aspecto teórico por trás da informalidade no mercado de trabalho, o surgimento do empreendedorismo por necessidade, a profissão de Maquiador e o papel do Microempreendedor Individual (MEI) para essa profissão, conforme são apresentados nas próximas subseções.

\subsection{Da informalidade ao empreendedorismo}

Existem, na literatura, vários discursos em relação à informalidade do mercado devido à complexidade das relações estabelecidas entre economia formal e informal, conforme explicam Maciel e Oliveira (2018). Segundo as autoras, a informalidade vem ganhando importância mesmo nas economias com mercados de trabalho estruturados.

De acordo com Lima (2010) e Siqueira, Rocha e Telles (2013), a informalidade é um tipo de trabalho não regulamentado que se destaca em setores de baixa produtividade e rentabilidade, citando, como exemplos, a pequena produção familiar, atividades comerciais ambulantes e outras atividades. Segundo os autores, a opção pela informalidade, além de ser de ordem financeira, pode ocorrer por traços familiares, jornada de trabalho flexível, entre outros motivos.

Muitas vezes, a informalidade é considerada uma alternativa para enfrentar o desemprego, uma vez que o indivíduo precisa exercer alguma atividade que promova a sua subsistência (MORAES, 2008). Assim, os motivos que podem levar o indivíduo à informalidade, segundo Siqueira, Rocha e Telles (2013), são: preços diferenciados; a fiscalização frágil por parte do governo; o não pagamento de impostos, custos trabalhistas e regulatórios e a redução de despesas decorrentes de adaptação a regras contábeis. Os autores atentam, também, para suas desvantagens: pagamento de multas; punições pela violação das leis; dificuldade no acesso ao sistema judiciário; o não acesso a linhas de crédito destinadas às empresas e a impossibilidade de cobertura previdenciária.

Cabe destacar, ainda, que a informalidade afeta diretamente o crescimento econômico do país, porque, conforme mostra Francisco (2019), muitas mercadorias são fabricadas e vendidas sem o pagamento de impostos, afetando negativamente o Produto Interno Bruto (PIB). Ainda de acordo com o Francisco (2019), no Brasil, se houvesse a formalização da atividade informal, isso poderia acarretar em aumento de $30 \%$ no PìB.

Relacionada ao contexto da informalidade, apresenta-se o empreendedorismo, seja por oportunidade, seja por necessidade. Quanto ao empreendedorismo por oportunidade, "o indivíduo é motivado a empreender, pela percepção de uma oportunidade ou um nicho de mercado pouco explorado" (FAGUNDES, 2017, p. 1). Segundo o autor, muitas vezes, o empreendedorismo ocorre por necessidade, ou seja, "o indivíduo que é motivado a empreender quando não tem alternativa razoável de ocupação e renda". Dessa forma, define-se o empreendedorismo por necessidade quando o empreendedor abre uma empresa pressionado pela ausência de alternativas de trabalho e renda (VALE; CORRÊA; REIS, 2014). Ainda nesse sentido, Silva (2014, p. 16) relata que:

O Empreendedor por Necessidade cria o próprio negócio por falta de alternativa. Geralmente não tem acesso ao mercado de trabalho ou foi demitido. Só o resta a opção de trabalhar por conta própria. Se envolve em negócios informais, desenvolvendo tarefas simples, prestando serviços e como resultado pouco retorno financeiro. (SILVA, 2014, p. 16).

Isso reforça que, como mostrado pela definição de Silva (2014), apresentada anteriormente, é através da necessidade de encontrar um lugar no mercado de trabalho que o profissional opta por se tornar um empreendedor. Para Vale, Corrêa e Reis (2014), o empreendedorismo por necessidade tem sido associado às condições de queda da atividade econômica, que gera desemprego e diminui a oferta de emprego. Assim, as pessoas buscam iniciar uma atividade que possibilite sua sobrevivência econômica, agindo por necessidade com características particulares, visando a oportunidades lucrativas, satisfazendo as necessidades e satisfazendo das pessoas.

Ainda nesse sentido, ressalta-se sobre o empreendedorismo como oportunidade. Quando há uma crise e queda na economia, o empreendedorismo surge, com novas tendências e oportunidades, para atender às necessidades das pessoas. E, dentro dos diversos ramos em que o empreendedor pode atuar, o da estética e beleza tem se destacado pelo crescimento do mercado e das oportunidades. Nesse ramo, um dos profissionais de destaque é a profissão de maquiador(a).

Assim, tanto a informalidade quanto o papel de empreender podem surgir a partir do crescimento do mercado em determinadas áreas, como tem ocorrido com o setor de beleza. Hoje, as pessoas, tanto homens quanto mulheres, procuram se sentir melhor, elevando sua autoestima e adotando novos padrões de beleza. Com isso, a maquiagem passou a fazer parte do dia a dia delas, fazendo com que várias pessoas buscassem qualificação e atuassem como maquiadores, muitas vezes, de maneira informal. 


\subsection{A formalização da profissão de maquiador}

O ramo da maquiagem é um setor que vem se expandindo conforme os padrões de beleza existentes e com o crescimento do setor de cosméticos no mercado. De acordo com Oneda, Perin e Thives (2008), a maquiagem é um recurso considerado seguro, prático, e de fácil acesso a todas as classes e auxilia na construção de uma imagem pessoal positiva para uma melhor aceitação do indivíduo no mercado de trabalho e no convívio social.

Hoje, a maquiagem é considerada uma arte de embelezar, e o maquiador pode ser considerado um artista, um consultor ou apenas executor de uma estética alheia, determinada pelo cliente (ONEDA, PERIN e THIVES, 2008).

A Lei $n^{\circ} 12.592 / 2012$, que dispõe sobre o exercício das atividades profissionais de Cabeleireiro, Barbeiro, Esteticista, Manicure, Pedicure, Depilador e Maquiador (BRASIL, 2012), reconheceu as atividades do maquiador como profissão. Este profissional trabalha em diversos segmentos, como TV, cinema, editoriais de moda, desfiles, salões de beleza, entre outros, mas, muitas vezes, prestam atendimento personalizado em domicílio em suas próprias residências (OLIVEIRA, 2015).

Entretanto, embora seja reconhecido como uma profissão, existe uma parcela significativa dos profissionais nessa área que atuam de maneira informal ou, regulamentado pela Lei Complementar $\mathrm{n}^{\circ}$ 128/2008, que instituiu uma nova forma jurídica, o MEI.

A Lei Complementar ํㅜ 128 de 2008 criou a figura do MEl e modificou partes da Lei Geral da Micro e Pequena Empresa (Lei Complementar 123/2006). Entende-se que isso pode contribuir para a redução da informalidade, uma vez que criou condições especiais para que o trabalhador conhecido como informal possa se tornar um MEI legalizado. "A formalização do MEI visa o aumento da arrecadação, além de dar uma atenção para a realidade das demandas sociais" (ARRUDA, 2017, p. 13).

O MEI, sistema empresarial, tem como principal objetivo a formalização de trabalhadores que exercem suas funções por conta própria, desfrutando, assim, dos benefícios por ela gerados. Para se tornar MEI, o empresário individual necessita seguir regras impostas pelo sistema que são renováveis periodicamente. Atualmente (2021), o limite de faturamento é de $R \$ 81.000,00$ anual (esse valor é alterado conforme a mudança anual do salário mínimo); ou $\mathrm{R} \$ 6.750,00$ mensais (média) (SEBRAE, 2018). O Microempreendedor não contempla profissões que necessitam de "curso superior" para o desenvolvimento de sua atividade, porém, ao se formalizar, é primordial que observe se a atividade a ser explorada encontra-se regulamentada pelo sistema. Além disso, cada MEI pode contratar somente um funcionário, recebendo salário mínimo ou piso de categoria (PORTAL MEI, 2018).

Importante destacar a importância do MEI para os microempreendedores dos ramos de pequenos negócios como o profissional Maquiador, pois, saindo da informalidade, a profissão pode ser mais valorizada no contexto econômico atual. Estão fora deste conceito, conforme a Lei Complementar 123/2006, as profissões regulamentadas de caráter técnico, científico ou literário como advogados, médicos e engenheiros.

Destaca-se, ainda, que, conforme a Resolução Comitê Gestor do Simples Nacional (CGSN) 140/2018, além de não poder ter um faturamento acima de $R \$ 81.000,00$, não poderá ser MEI a pessoa que:

a) Exerce atividade não relacionada no Anexo XI[3] da Resolução CGSN 140/2018.

b) Participe de outra empresa como titular, sócio ou administrador.

c) Possua mais de um estabelecimento.

d) Contrate mais de um (1) empregado.

e) Caso tenha empregado, pague mais que 1 salário mínimo ou o piso da categoria.

f) Utilize a condição de MEI para fragilizar a legislação trabalhista.

g) Descumpra normas municipais como exercer comércio ambulante sem permissão, etc.

h) Possua sócio.

Até 2018, ocorreram 7.510.771 registros de MEls no Brasil, uma oportunidade tanto para aqueles que nunca empreenderam, quanto para aqueles que já trabalhavam na informalidade. Porém, muitos microempreendedores ainda encontram dificuldades na gestão de seu empreendimento em relação à conquista de clientes, à própria gestão do negócio, à concorrência, às compras, ao ponto comercial e às obrigações legais (LIMA; LOPES, 2019).

Importante destacar a necessidade de que os MEls tenham conhecimento mínimo sobre o processo financeiro para conduzir seus negócios. Para isso, conforme explicam Lima e Lopes (2019), devem buscar capacitação sobre o controle financeiro, crédito e financiamento, propaganda e marketing e melhoria da qualidade de produtos e serviços.

Quando um empreendedor opta por atuar na informalidade, existem quatro grandes problemas, mas que podem ser resolvidos facilmente ao se formalizarem, como explicam Lifschiite et al. (2016), sendo eles:

- A falta de seguridade social prejudica o próprio empreendedor, sendo, consequentemente, por isso que o SEBRAE tem como o objetivo a legalização de 10 milhões de empreendedores. 
- A comprovação de renda, que impossibilita o aluguel de casas, compras de veículos e até mesmo obtenção de créditos bancários.

- A falta de comprovação da compra de mercadorias, fazendo com que os famosos "rapas" - fiscais municipais ou de estado - levassem as mercadorias desses informais.

- As reivindicações trabalhistas, já que não havia como registrar o empregado anteriormente devido às altas taxas de contribuição previdenciária.

Segundo o Portal do Empreendedor (2013), a Lei Complementar 128/2008 promove benefícios aos trabalhadores informais, com o objetivo de legalização desses profissionais.

Ao ingressar no MEl, o empreendedor passa a dispor de vantagens (SEBRAE, 2018):

- Formalização simplificada, rápida e gratuita.

- Direito ao CNPJ, Certificado do Microempreendedor Individual, Inscrição Municipal.

- Benefícios Previdenciários: aposentadoria por idade, aposentadoria por invalidez, auxílio-doença, salário-maternidade, pensão por morte e auxílio-reclusão.

- Dispensa da escrituração contábil.

- Pode emitir notas fiscais (obrigatório apenas quando for vender para outra empresa), com maiores chances de ser contratado por outras empresas e pelo governo, conquistando, assim, novos clientes.

- Mesmo quando emitir para outra empresa, o MEl pode ser dispensado da emissão de nota fiscal se a empresa emitir nota de entrada. Cfe. inciso, § 2º, art. 7º, Resolução CGSN no 10/2007.

- Possibilidade de legalizar a contratação de 01 funcionário, diminuindo os riscos de problemas trabalhistas.

- Alvará de funcionamento provisório por 06 meses.

- Isenção de taxas de Alvarás, Licenças e Cadastros (as renovações do Alvará, Licença e Cadastros para funcionamento também são gratuitas. A previsão legal para impossibilidade de cobrança de 08 taxas e emolumentos é estabelecida pela Lei Complementar ํo 123/2006 e suas alterações posteriores, $\S 3^{\circ}$ do artigo $4^{\circ}$ ).

Para a família:

- Pensão por morte: a partir do primeiro pagamento em dia. O pagamento não poderá ocorrer após o óbito.

- Auxílio-reclusão: a partir do primeiro pagamento em dia. O pagamento não poderá ocorrer após a reclusão.

Além disso, de acordo com Silva (2014), aquele que se formaliza adquire a facilidade de abertura de contas em bancos públicos como Banco do Brasil e obtenção de créditos e empréstimos. ao MEI.

A seguir, apresenta-se, com base na literatura, estudos que ponderam sobre os benefícios do registro

Quadro 1 - Benefícios para a formalização do MEI, de acordo com a literatura

\begin{tabular}{|l|l|}
\hline \multicolumn{1}{|c|}{ Benefícios } & \multicolumn{1}{|c|}{ Fonte } \\
\hline Direitos previdenciários & Vasconcelos (2016) \\
\hline $\begin{array}{l}\text { Possibilidade de emissão de nota fiscal e } \\
\text { comprovação de renda }\end{array}$ & Silva (2014), Vasconcelos (2016) \\
\hline Facilidades no acesso ao crédito e a financiamentos & Silva (2014) \\
\hline Baixa burocracia e facilidades na formalização & $\begin{array}{l}\text { Siqueira, Rocha e Telles (2013), Oliveira (2014), } \\
\text { Vasconcelos (2016) }\end{array}$ \\
\hline $\begin{array}{l}\text { Redução dos impostos e redução nas obrigações } \\
\text { acessórias exigidas }\end{array}$ & Siqueira, Rocha e Telles (2013), Oliveira (2014) \\
\hline
\end{tabular}

Fonte: Elaborado pelas autoras

\section{METODOLOGIA}

Trata-se de um estudo survey descritivo de caráter qualitativo e quantitativo. De acordo com Sampieri, Collado e Lúcio (2013), a pesquisa survey é indicada para obtenção de informações sobre um determinado grupo de pessoas. Além disso, segundo Vergara (2000), a pesquisa descritiva expõe características de determinada população ou de determinado fenômeno. Pode, também, estabelecer correlações entre variáveis e definir sua natureza. Não tem compromisso de explicar os fenômenos que descreve embora sirva de base para tal explicação. 
Sobre a pesquisa qualitativa, Gerhardt e Silveira (2009) alegam que esta não se preocupa com representatividade numérica, mas sim com o aprofundamento da compreensão de um grupo social, de uma organização etc. Quanto ao método quantitativo, Marconi e Lakatos (2011) afirmam que é caracterizado pelo emprego da quantificação, cujos pesquisadores valem-se de amostras amplas e de informações numéricas.

No sentido qualitativo, as informações serão provenientes de fontes documentais, além da aplicação de questionários. Para coleta de dados secundários, foram consultados órgãos oficiais e instituições relacionadas com o pequeno empreendedor como o SEBRAE, a Prefeitura Municipal de Ponte Nova e a Associação Comercial e Industrial de Ponte Nova (ACIP/CDL).

A aplicação do questionário, autorizado pelo Comitê de Ética e Pesquisa (CEP) da Faculdade Dinâmica do Vale do Piranga por meio do Certificado de Apresentação de Apreciação Ética (CAAE) número 29019820.9.0000.8063, teve como participantes da pesquisa profissionais de maquiagem que atuam no município de Ponte Nova em salões de beleza, bem como profissionais que atuam por conta própria. O critério de inclusão para a seleção dos participantes nesta pesquisa foi considerar os profissionais ativos nas redes sociais e encontrados por meio da plataforma de pesquisa digital, o Google. Desse modo, o método de exclusão ocorreu diante da não identificação destes profissionais nos órgãos e plataformas. Os questionários foram propagados de forma on-line, de março a agosto de 2020, por um formulário criado no Formulário Google.

Os questionários (23), classificados como semiestruturados, garantiram a confidencialidade dos dados disponibilizados pelos servidores, por meio da apresentação do termo de consentimento livre e esclarecido. Foi garantido o anonimato no estudo, bem como a liberdade de se recusarem a fazer parte da pesquisa, a qualquer momento, caso desejassem.

De acordo com Gerhardt e Silveira (2009), com esses questionários, o pesquisador pode organizar um conjunto de questões (roteiro) sobre o tema que está sendo estudado, podendo também incentivar o entrevistado a falar livremente sobre assuntos que vão surgindo como desdobramentos do tema principal.

A estruturação dos questionários foi assim realizada: primeiramente, houve perguntas sobre o perfil dos profissionais de maquiagem que atendem no município de Ponte Nova - MG; em seguida, foram realizados questionamentos tendo por base os benefícios para a formalização do MEl já elencados no Quadro 1.

O estudo contou, ainda, com uma pesquisa documental que inclui o estudo da Lei Complementar 128/2008 que alterou a Lei Complementar 123/2006 (Lei do Microempreendedor Individual).

Para a análise dos dados, utilizou-se a análise de conteúdo categorial temática com grade fechada (VERGARA, 2012). Nesse caso, as categorias foram definidas com base em conhecimentos provenientes da literatura (já elencados no Quadro 1 - Benefícios para a formalização do MEI), buscando-se identificá-las a partir das respostas dos questionários.

\section{RESULTADOS}

Os resultados são apresentados a partir de duas subseções. A primeira apresenta as informações coletadas a partir dos dados secundários; a segunda, através das informações da pesquisa de campo.

\subsection{Levantamento de dados secundários sobre o número de Maquiadoras registradas pelo MEI em Ponte Nova-MG}

A cidade de Ponte Nova, localizada na Zona da Mata de Minas Gerais, possuía em 2019 uma população estimada em 59.742 habitantes (IBGE, 2020). De acordo com Xavier (2018), a economia que antes tinha o Produto Interno Bruto (PIB) representado, principalmente, pela agricultura (com o cultivo da cana de açúcar, por exemplo) se voltou nos últimos anos para o setor de serviços, em que esse teve $53,4 \%$ de participação no PIB bruto municipal em 2015.

Tendo em vista a importância do setor terciário (que engloba as atividades de serviços e comércio de produtos) para a economia pontenovense, buscaram-se essas informações através dos registros disponibilizados pela Prefeitura Municipal. Foi possível identificar que existe cerca de 5.000 pessoas jurídicas, dentre elas, 2.250 (45\%) são empresas do ramo comercial, e 2.300 (55\%) são prestadores de serviços.

Nesse sentido, salienta-se que, para realizar o registro de todas as pessoas jurídicas, a Prefeitura utiliza a Classificação Nacional de Atividades Econômicas (CNAE) por ser a oficial adotada pelo Sistema Estatístico Nacional do Brasil e pelos órgãos federais, estaduais e municipais gestores de registros administrativos e demais instituições do Brasil. Entretanto, embora a classificação do CNAE seja a mais adequada para os municípios, ela não possibilita identificar o número exato de profissionais ligados especificamente, ao segmento da maquiagem - objeto de interesse deste estudo. O grupo descrito como "Atividades de estética e outros serviços de cuidado com a beleza (9602-5/02)", que melhor se enquadra para o profissional da maquiagem no CNAE, possui, de acordo com a Prefeitura, 60 profissionais inscritos no município. Vale salientar que o grupo indicado pode englobar maquiadores e outros profissionais como cabeleireiros, design 
de sobrancelha, esteticista, massagistas, entre outros.

Com o objetivo de ampliar as informações relacionadas ao tema abordado, por meio de dados secundários, realizou-se uma pesquisa na mala direta ${ }^{1}$ da Associação Comercial e Industrial de Ponte Nova (ACIP/CDL). De acordo com a Associação Comercial (2020), as associações comerciais são importantes por atuarem na defesa dos interesses da classe empresarial, como também fomentar o comércio local junto aos órgãos públicos.

De acordo com a ACIP, estão cadastradas em 2020, na Associação, 538 empresas, mas apenas 12 delas são formalizadas pelo sistema do Microempreendedor Individual (MEI) e, dentre elas, somente uma é enquadrada no CNAE, objeto deste estudo (9602-5/02).

Em princípio, tanto a informação disponibilizada pela Prefeitura quanto pela ACIP, já dá indícios de que 15 profissionais do ramo da maquiagem possuem formalização ou procuram manter atualizado o registro nos órgãos pertinentes. Nesse sentido, buscando ampliar as informações a respeito do tema. Este estudo aplicou questionários em formato digital, e os resultados são apresentados na subseção a seguir.

\subsection{Características do profissional de Maquiagem em Ponte Nova-MG}

Foram convidados 25 profissionais de Maquiagem para participarem do estudo, mas somente 23 responderam ao questionário disponibilizado pelas redes sociais. Entre os respondentes, 22 são do sexo feminino, sendo 18 na faixa etária de 18 a 30 anos, 3 de 31 a 50 anos e 1 na faixa de 51 a 70 anos e apenas 1 do sexo masculino, na faixa etária de 18 a 30 anos. A relação da faixa-etária e sexo dos respondentes estão descritos no Tabela 1.

Tabela 1 - Relação: Sexo e Faixa-Etária dos respondentes

\begin{tabular}{ccccc} 
Sexo & $\mathbf{1 8}$ a $\mathbf{3 0}$ anos & $\mathbf{3 1}$ a $\mathbf{5 0}$ anos & $\mathbf{5 1}$ a $\mathbf{7 0}$ anos & TOTAL \\
Feminino & 18 & 3 & 1 & 22 \\
Masculino & 1 & - & & 1 \\
TOTAL & $\mathbf{1 9}$ & $\mathbf{3}$ & $\mathbf{1}$ & $\mathbf{2 3}$ \\
\multicolumn{5}{c}{ Fonte: Dados da Pesquisa. }
\end{tabular}

Ao analisar o sexo e a faixa-etária dos respondentes, pode-se verificar que $82,60 \%$ tinham idade de 18 a 30 anos e $13,05 \%$ de 31 a 50 anos e $4,35 \%$ na faixa de 51 a 70 anos.

Os dados evidenciam que, mesmo que existam estudos (SILVA, 2014; LANÖE; MATTOS, 2019) que indiquem que a maquiagem não possui gênero, para os profissionais de maquiagem de Ponte Nova - MG, isso não acontece, pois mais de $95 \%$ dos profissionais do ramo são mulheres. Além disso, a maioria dos respondentes se encontra na faixa de 18 a 30 anos, o que difere do estudo de Silva (2014) que indicou a prevalência na faixa de 31 a 40 anos.

Com relação à predominância do sexo feminino na profissão de maquiador em Ponte Nova, Yannoulas (2013) aponta que os fatores socioculturais, ancorados no sistema de gêneros, são imprescindíveis para explicar tal discrepância. Isso porque fatores como o desenvolvimento de habilidades e gosto pela profissão podem estar relacionados aos brinquedos destinados às crianças do sexo feminino em que, na maior parte das vezes, são destinados ao preparo do papel de mãe e esposa (objetos como bonecas, itens de casa e objetos de beleza) (YANNOULAS, 2013). Entretanto, Silvia, Fialho e Queiroz (2018) mostram que há um avanço significativo na busca pela equidade no ensino e na área profissional, mas esses ainda não puderam ser observados por este estudo.

A maioria dos respondentes têm menos de cinco anos na profissão $(60,87 \%)$, representando 14 maquiadores, cinco (21,73\%) têm de 5 a 10 anos, três (13,05\%) têm de 10 a 20 anos e um (4,35\%) tem mais de 20 anos. Com relação ao estado civil, 12 respondentes disseram estar solteiros $(52,17 \%)$, sete casados $(30,43 \%)$, três divorciados $(13,05 \%)$ e um $(4,35 \%)$ preferiu não informar.

Fez-se um comparativo entre o estado civil e a renda dos participantes. Dentre as pessoas solteiras, três $(25 \%)$ têm renda de até 1 salário mínimo, seis $(50 \%)$ têm renda de 1 a 3 salários e três $(25 \%)$ têm renda maior que 3 salários mínimos. Todas as sete (100\%) pessoas casadas têm uma renda de 1 a 3 salários, o mesmo ocorre com as três (100\%) respondentes divorciadas e uma pessoa que não informou o estado civil. Pode-se perceber que, dos clientes respondentes, a maioria é constituída por pessoas solteiras, com renda

\footnotetext{
1 Sistema de divulgação de mensagem publicitária, marketing, avisos, declarações, cobrança, entre outros, podendo ser enviada pela internet ou correio tradicional. É bastante eficaz particularmente para a divulgação de produtos, serviços ou para fins informativos (FRANÇA, 2020).
} 
familiar de 1 a 3 salários mínimos, conforme mostra a Figura 1. Diante do exposto, não se pode afirmar que o estado civil interfere na profissão de maquiador.

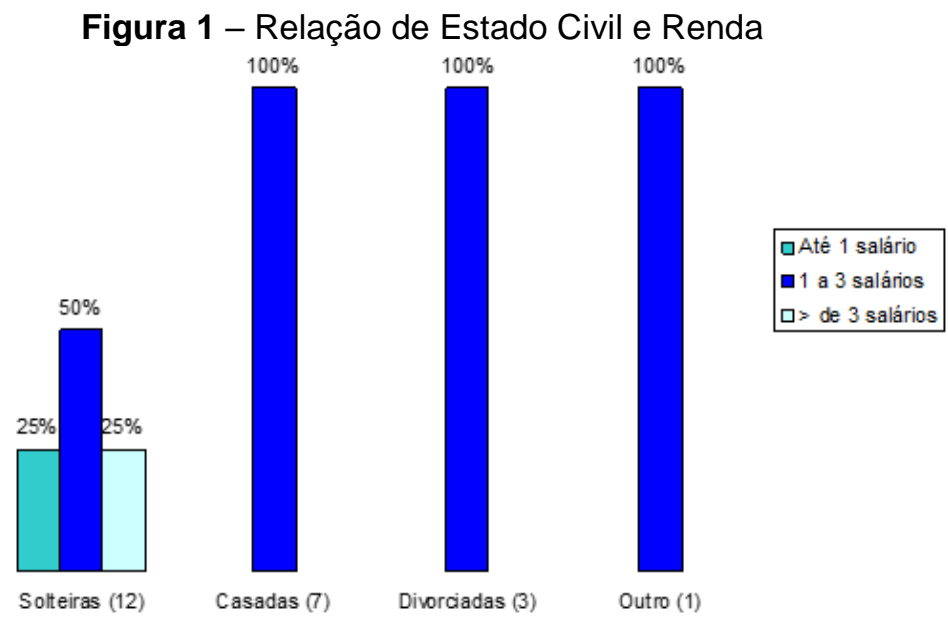

Fonte: Dados da pesquisa

Os resultados ainda revelam que a profissão de maquiagem não proporciona a principal renda da casa. Ao serem questionados sobre isto, $15(56,52 \%)$ dos 23 respondentes alegaram que o que ganham na profissão não é a principal renda.

Do total de respondentes, $15(65,21 \%)$ não têm filhos e $8(34,79 \%)$ têm. Com relação ao nível de escolaridade, 56,52\%, que representam 13 respondentes, têm Ensino Médio Completo, 8,70\% (dois respondentes) têm Ensino Médio Incompleto, 8,70\% (dois respondentes) possuem Ensino Superior Completo e 6 respondentes, que equivalem a 26,08\%, têm Ensino Superior Incompleto. Constatou-se que os profissionais de maquiagem respondentes já concluíram pelo menos a Educação Básica, o que pode fazer com que as pessoas tenham mais acesso à informação sobre a maquiagem, através da internet, de redes sociais e de cursos relacionados à profissão, uma vez que os $23(100 \%)$ respondentes já participaram de cursos de aperfeiçoamento na área e estão satisfeitos com a profissão.

Sobre a formalidade da profissão, $13(56,52 \%)$ respondentes atuam de maneira formal, $12(52,17 \%)$ se tornaram MEI e um atua como empregado em um salão de beleza. Contudo, 10 respondentes $(43,48 \%)$ ainda atuam na informalidade. O resultado encontrado corrobora com os dados apresentados pela pesquisa do Instituto Brasileiro de Geografia e Estatística (IBGE), que apresenta que os trabalhadores informais representam a principal fonte de ocupação de mais de $40 \%$ da população de 21 estados. E, pode-se afirmar ainda que, com a crise financeira causada pela Covid-19, existe alta probabilidade de crescimento do setor informal (FOLHA DE SÃO PAULO, 2020).

O tempo de atuação como MEl encontra-se na Figura 2.

Figura 2 - Tempo de atuação como MEI

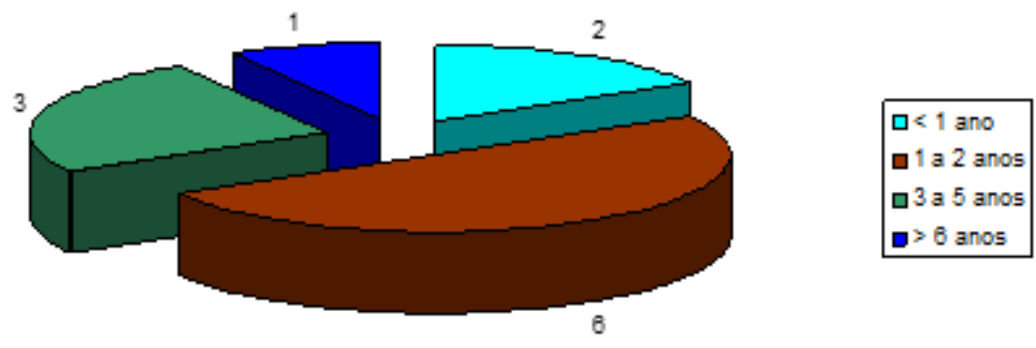

Fonte: Dados da pesquisa

Com relação ao tempo que os profissionais estão formalizados com o $\mathrm{MEI}$, pode-se dizer que é bem recente, considerando que a Lei Complementar ํㅜ 128, que instituiu o MEl, é de 2008. Deve-se considerar também que a maioria dos respondentes nesta pesquisa são jovens na faixa de 18 a 30 anos.

Dos profissionais MEls respondentes, quatro $(33,33 \%)$ tomaram conhecimento sobre o MEl por meio do SEBRAE, dois $(16,67 \%)$ por meio da internet e seis $(50 \%)$ por outros meios. Isso mostra que a maioria 
buscou informação sobre o assunto por interesse próprio e, ao buscar atendimento para o cadastrado no MEI, $8(66,67 \%)$ encontraram facilmente informações para sua formalização, três $(25 \%)$ conseguiram atendimento imediato e realizaram sua formalização no mesmo momento e um $(8,33 \%)$ verificou a necessidade de buscar informações adicionais através de outro meio.

Estudo descritivo, baseado em procedimento quantitativo, realizado por Siqueira, Rocha e Telles (2013), com uma amostra de 40 microempreendedores brasileiros do município de Diadema, no Estado de São Paulo, e de 25 empreendedores informais do mesmo município mostrou que, dos $40 \mathrm{MEls}$, quatro também tomaram conhecimento sobre o MEI por meio da SEBRAE, três por meio da internet e 33 por outros meios, como a Prefeitura Municipal e as orientações de contadores.

Em complemento, Silva (2014) enfatizou, em seu estudo, que, quando há o acesso às informações de forma adequada, o governo, por meio da nova lei do MEI, tem conseguido atingir o seu objetivo, trazendo para a formalidade os pequenos trabalhadores que não têm condições de arcar com custos de uma empresa normal. Ademais, ainda de acordo com o mesmo autor, $66,67 \%$ dos respondentes consideram-se satisfeitos com o programa do $\mathrm{MEI}$, isso pelas vantagens e benefícios que, enquanto trabalhador informal, não teriam acesso.

Soma-se aos fatores apresentados, a questão do empreendedorismo enquanto necessidade ou oportunidade. Isso porque, no contexto nacional, o número de profissionais MEls tem crescido, mesmo com a crise provocada pelo Coronavírus, em 2020, ultrapassando a marca de 10 milhões de Microempreendedores Individuais, conforme divulgado pelo Portal do Empreendedor (2020).

Além do exposto, algumas perguntas foram direcionadas somente aos profissionais que se tornaram MEls e os resultados encontram-se no Quadro 2. Nem todas as alternativas foram destacadas pelos respondentes.

Quadro 2 - Perguntas direcionadas aos respondentes que se tornaram MEls.

\begin{tabular}{|c|c|c|c|c|c|c|}
\hline $\begin{array}{l}\frac{9}{0} \\
\stackrel{0}{5} \\
\frac{5}{0} \\
\frac{0}{0} \\
0\end{array}$ & 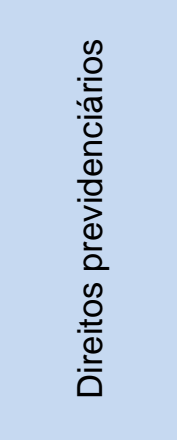 & 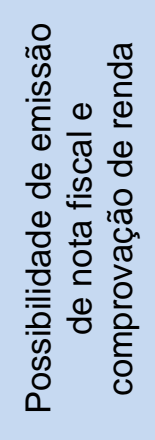 & 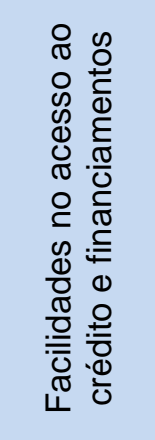 & 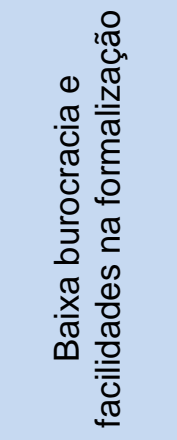 & 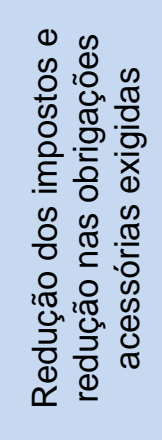 & 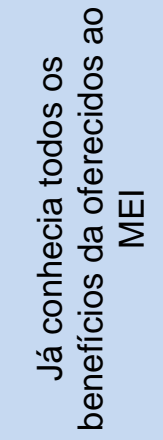 \\
\hline $\begin{array}{c}\text { Qual dos benefícios } \\
\text { abaixo foi à principal } \\
\text { motivação para a } \\
\text { formalização através } \\
\text { do MEI? }\end{array}$ & $5(41,7 \%)$ & $1(8,3 \%)$ & $3(25 \%)$ & $1(8,3 \%)$ & $2(16,7 \%)$ & - \\
\hline $\begin{array}{l}\text { Algum dos benefícios } \\
\text { abaixo não era } \\
\text { conhecido antes de } \\
\text { você se formalizar? }\end{array}$ & $1(8,3 \%)$ & - & $1(8,3 \%)$ & $4(33,3 \%)$ & $2(16,7 \%)$ & $4(33,3 \%)$ \\
\hline $\begin{array}{l}\text { Qual benefício você } \\
\text { considera que terá } \\
\text { maior relevância no } \\
\text { seu dia-a-dia? }\end{array}$ & $5(41,7 \%)$ & $1(8,3 \%)$ & $3(25 \%)$ & $1(8,3 \%)$ & $2(16,7 \%)$ & - \\
\hline
\end{tabular}

Fonte: Dados da Pesquisa

Ao serem questionados sobre quais os benefícios garantidos em lei não atenderam às suas expectativas, todos os profissionais MEls responderam que todos os benefícios atenderam às expectativas e quanto à vantagem considerada mais relevante para o $\mathrm{MEI}$, comparativamente a uma empresa não enquadrada como MEI, três (25\%) apontaram a baixa carga tributária, tendo o imposto recolhido de forma fixa, quatro $(33,34 \%)$ apontaram o acesso a juros reduzidos e taxas diferenciadas para obter créditos e financiamentos, um $(8,33 \%)$ apontou a simplicidade e isenção dos custos para formalização e quatro $(33,34 \%)$ 
apontaram como vantagem, a dispensa de contabilidade, sendo necessária apenas a manutenção de controles simplificados. Além disso, existe a facilidade na compra de produtos, afastamento quando necessário, direito a contratar um funcionário e segurança ao registrar uma firma.

Corroborando com o estudo de Siqueira, Rocha e Telles (2013) apontou como vantagens: a segurança jurídica, uma vez que o empreendedor que se formaliza acredita que está seguro quanto ao seu negócio, entendendo que tem o amparo da lei para protegê-lo, além do acesso a serviços bancários, seguido da cobertura previdenciária. Ademais, o estudo de Silva (2014) apontou que 72,25\% dos respondentes foram motivados pelos benefícios que a formalização traz à empresa como a criação do CNPJ, obtenção de crédito e comprovação de renda.

Vale chamar a atenção que, no segmento analisado por esse estudo, o maior benefício identificado são os direitos previdenciários e esse fator também é levantado como sendo a principal vantagem trazida ao dia a dia do profissional da maquiagem. Isso se torna relevante, pois essa informação pode ser utilizada para nortear políticas públicas com intuito de aumentar a formalização no segmento. Entretanto, Pereira (2020) apresenta que estratégias para garantir direitos previdenciários e trabalhistas podem ser complexas, principalmente, quando se trata de trabalho produtivo das mulheres.

É possível observar também que, de acordo com o Quadro 2, boa parte dos respondentes tinham conhecimento de todos os benefícios do MEI e que todos os 12 respondentes que se tornaram MEls, consideram fácil o processo de adequação ao MEI. Entretanto, uma parcela significativa ainda não tinha conhecimento sobre a baixa burocracia e a facilidade de adesão ao regime. Nesse sentido, existem esforços significativos na literatura para mostrar ao MEI a importância do auxílio do contador (MORAES, 2019; ARAÚJO e ANJOS, 2021), mas também da sua não obrigatoriedade devido à facilidade de execução dos processos. Os resultados vão ao encontro do estudo apresentado por Silva (2014) a partir do qual mostrou que o microempreendedor tem fácil acesso às informações para a adesão, mas o acesso às vantagens e aos benefícios proporcionados pela lei ainda continuam burocratizados. Isso pode ocorrer por falta de informação adequada e por empecilhos ligados à própria gestão do negócio (OLIVEIRA et al., 2017).

Assim, os dados deste estudo indicam que, de forma geral, boa parte dos maquiadores de expressão de Ponte Nova possuem conhecimento sobre os benefícios trazidos pelo MEI e optam pela formalização, principalmente pelo benefício previdenciário e pela maior segurança. Porém, ainda há espaço para a maior discussão sobre a temática, com a finalidade de ampliar o conhecimento do processo de formalização.

\section{CONSIDERAÇÕES FINAIS}

O presente estudo teve o objetivo de apresentar o profissional do ramo de maquiagem na cidade de Ponte Nova, Minas Gerais, e a sua relação com o mercado (in)formal no município. A partir disso, foi possível analisar os reflexos trazidos pelo MEI aos profissionais de maquiagem no município de Ponte Nova-Minas Gerais, bem como: comparar a relação entre os profissionais legalizados e aqueles que atuam na informalidade e destacar a importância do MEI para os profissionais de maquiagem. O trabalho destacou que o profissional de Maquiagem, ao se tornar um MEI, adquire segurança jurídica e benefícios amparados por lei. Como vantagens para os profissionais legalizados, em relação aos da informalidade, o estudo apontou: direitos previdenciários, a possibilidade de emissão de nota fiscal e comprovação de renda, facilidades no acesso ao crédito e financiamentos, a baixa burocracia e facilidades na formalização, a redução dos impostos e redução nas obrigações acessórias exigidas, além de descontos em impostos e soluções de situações em momento da pandemia do Coronavírus.

Dessa forma, o estudo avança com relação à literatura existente ao discutir uma profissão ainda pouco estudada e ao associar a discussão do profissional Maquiador ao empreendedor. Não obstante, o estudo contribui ao identificar, junto aos maquiadores de Ponte Nova, fatores que podem contribuir para o aumento da formalização no segmento. Por exemplo, identificou-se que políticas públicas voltadas para divulgação de benefícios previdenciários conquistados através da formalização como MEl podem trazer bons resultados, já que esse foi o principal fator que motiva a formalização e que traz mais benefício, no dia a dia, para o segmento.

Sobre as implicações empíricas, o estudo denota a importância da formalização no mercado de trabalho, esclarece as principais vantagens e suscita, para que aqueles que ainda atuam na informalidade, possam obter certa segurança em exercer a profissão.

Como limitação do estudo, é possível apontar a baixa disponibilidade de dados secundários relacionados ao tema, além do registro da prefeitura possuir poucas informações descritivas. Não obstante, o período de aplicação dos questionários foi prejudicado devido às medidas de restrição sanitária geradas pela pandemia, o que impossibilitou a realização de uma entrevista pessoalmente, o que poderia ampliar a quantidade e a qualidade das informações coletadas.

Como forma de garantir a continuidade de estudos futuros, sugerem-se novas pesquisa sobre o tema, que destaquem a importância das leis e o papel governamental para a formalização de negócios. Ademais, 
sugerem-se estudos empíricos que tratem do tema em novas localidades para que sirvam de referencial para futuros trabalhos acadêmicos e sejam meio de informação para pessoas que tenham interesse pela profissão.

\section{REFERÊNCIAS}

ARAÚJO, Fabrício Maximiano de; ANJOS, Mayara Abadia Delfino dos. A importância da contabilidade para o microempreendedor individual (mei). Revista GeTeC, v. 10, n. 33, 2021.

ARRUDA, Valdivanda Carneiro. Da Informalidade ao Microempreendedor Individual (MEI): Uma revisão sistemática. 2017, 31 f. Disponível em < http://www.repositorio.ufc.br/bitstream/riufc/30117/1/2017_dis_vcarruda.pdf> Acesso em 12 out 2019

ASSOCIAÇÃO COMERCIAL E INDUSTRIAL DO VALE DO PIRANGA (ACIP). O que é uma Associação Comercial?. Disponível em https://www.associacaocomercial.net.br/o-que-e-uma-associacao-comercial/. Acesso em 17 de ago. 2020.

BRASIL. LEI № 13.429, de 31 de março de 2017. Disponível em: http://www.planalto.gov.br/ccivil 03/ ato20152018/2017/lei/l13429.htm. Acesso em: jun. 2021.

BRASIL. LEI № 13.467, de 13 de julho de 2017. Disponível em: http://www.planalto.gov.br/ccivil 03/ ato20152018/2017/lei/l13467.htm. Acesso em: jun. 2021.

BRASIL Ministério da Economia. Brasil ultrapassa a marca de 10 milhões de Microempreendedores Individuais (MEls). Empreendedorismo. 2020. Disponível em < https://www.gov.br/economia/pt-

br/assuntos/noticias/2020/abril/brasil-ultrapassa-a-marca-de-10-milhoes-de-microempreendedores-individuais-meis> Acesso em 15 set 2020.

BRASIL. Resolução CGSN no 140, de 22 de maio de 2018. Dispõe sobre o Regime Especial Unificado de Arrecadação de Tributos e Contribuições devidos pelas Microempresas e Empresas de Pequeno Porte (Simples Nacional). 2018. Disponível em < http://normas.receita.fazenda.gov.br/sijut2consulta/link.action?idAto=92278>. Acesso em 12 out 2019.

CARVALHO, André Roncaglia de et al. Vulnerabilidade social e crise sanitária no Brasil. Cadernos de Saúde Pública, v. 37, p. e00071721, 2021.

CORREIO BRAZILIENSE. Mercado de cosméticos cresce, apesar da crise. Economia. Junho. 2019. Disponível em < https://www.correiobraziliense.com.br/app/noticia/economia/2019/06/06/internas_economia,760579/mercado-decosmeticos-cresce-apesar-da-crise.shtml>. Acesso em 12 out 2019.

FAGUNDES, Rosival. Empreendedorismo de oportunidade. Administradores. 2017. Disponível em < https://administradores.com.br/artigos/empreendedorismo-de-oportunidade>. Acesso em 17 nov 2020.

FAGUNDEZ, Ingrid. Como o desemprego está criando 'funcionários-polvo' e aumentando pressão sobre quem trabalha. BBC NEWS BRASIL. 2019. Disponível em < https://www.bbc.com/portuguese/brasil-38791173>. Acesso em 09 set 2019.

FÉLIX PARREIRA, C.; DE CARVALHO GODINHO, L. A.; CASTANHEIRA, M. E.; G. DA SILVA, A. L. Pesquisa de marketing aplicada a um centro de estética. LIBERTAS: Revista de Ciências Sociais Aplicadas, v. 8, n. 2, p. 47-69, 6 jul. 2019.

FOLHA DE SÃO PAULO. Informalidade Supera 50\% em 11 estados do país, diz IBGE. Disponível em https://folha.com/12cov5s0. Acesso em 15 de set de 2020.

FRANCISCO, Wagner de Cerqueria e. "Economia informal"; Brasil Escola. 2019. Disponível em: <https://brasilescola.uol.com.br/brasil/economia-informal.htm>. Acesso em 19 nov 2019.

GERHARDT, Tatiana Engel; SILVEIRA, Denise Tolfo. Métodos de Pesquisa. Editora da UFRGS. 1르로ão. Rio Grande do Sul. 2009.

IBGE. Instituto Brasileiro de Geografia e Estatística. PNAD Contínua Mensal: taxa de desocupação é de 14,1\% e taxa de subutilização é de $28,6 \%$ no trimestre encerrado em junho. Agência de Notícias IBGE. Disponível em $<$ https://agenciadenoticias.ibge.gov.br/agencia-sala-de-imprensa/2013-agencia-de-noticias/releases/31479-pnadcontinua-mensal-taxa-de-desocupacao-e-de-14-1-e-taxa-de-subutilizacao-e-de-28-6-no-trimestre-encerrado-emjunho\#: :text=A\%20taxa\%20de\%20desocupa\%C3\%A7\%C3\%A30\%20(14,2020\%20(13\%2C3\%25)> Acesso em outubro de 2021.

LANOE, Catherine; MATTOS, Thiago. A maquiagem tem um gênero? Olhares sobre a maquiagem masculina. dObra [s]-revista da Associação Brasileira de Estudos de Pesquisas em Moda, v. 12, n. 25, p. 230-235, 2019.

LIFSCHIITE, Jefferson Côrrea et al. Empreendedorismo e o micro empreendedor individual: uma abordagem sobre as vantagens e desvantagens do-MEI. Revista Caribeña de Ciencias Sociales, n. 2016_11, 2016.

LIMA, Herlem Kassia dos Santos; LOPES, Jessica Patrícia. Sustentabilidade econômica na gestão das microempresas de salões de beleza no município de Parauapebas-PA: fatores e resultados. Parauapebas, 2019. $55 f$.

LIMA, L. G.; NASSIF, V. M. J. Conjecturas entre indivíduo empreendedor e capital psicológico. Revista Brasileira de Administração Científica, v. 8, n. 1, p. 176-189, 2017. 
LEMOS, Adriana Maria; BORGES, Talilian; JÚNIOR, Mauricio Cezar Resende LEITE. Empreendedorismo em Centros de Estética. Revista de Iniciação Científica da Universidade Vale do Rio Verde, v. 7, n. 2, 2018.

MACIEL, Francieli Tonet; OLIVEIRA, Ana Maria Hermeto C. de. Informalidade e Segmentação do Mercado de Trabalho Brasileiro nos Anos 2000: Uma Decomposição Quantílica de Diferenciais de Rendimentos. Rev. econ. Contemp., v. 22, n. 2. Rio de Janeiro. Disponível em < http://www.scielo.br/scielo.php?script=sci_a

rttext\&pid=S1415-98482018000200204>. Acesso em 112 out 2019.

MARCONI, M. A.; LAKATOS, E. M. Metodologia cientifica. 6. Ed. São Paulo: Atlas. 2011.

MENDES, Jaqueline. Mercado de cosméticos cresce, apesar da crise: Depois de dois anos em ritmo lento, setor acelera $10,6 \%$ no primeiro trimestre. Diversificação de produtos, aumento do crédito e retomada da economia brasileira impulsionam os negócios. Correio Brasiliense, Economia, Brasília, 06 jun 2019. Disponível em

<https://www.correiobraziliense.com.br/app/noticia/economia/2019/06/06/internas_economia,760579/mercado-decosmeticos-cresce-apesar-da-crise.shtml>. Acesso em 09 set 2019.

MORAES, Carolina. Mercado de trabalho informal feminino: Revenda de Cosméticos, no Município de Florianópolis-SC. Monografia. Universidade Federal de Santa Catarina. Curso de Graduação Em Ciências Econômicas. 2008.

MORAIS, Maria Aparecida Silva; FEITOSA FILHO, Raimundo Ivan. A Relevância do Contador para o Microempreendedor Individual (MEI). ID on line REVISTA DE PSICOLOGIA, v. 13, n. 43, p. 480-489, 2019.

OLIVEIRA, Reginaldo Aparecido; CASTRO KRAKAUER, Patricia Viveiros; CODA, Roberto. Estudo exploratório sobre benefícios e dificuldades de ser um microempreendedor individual. South American Development Society Journal, v. 3, n. 09, p. 155-173, 2017.

OLIVEIRA, Nara Simone DE. A carreira de maquiadores: um estudo de trajetórias profissionais. Universidade Federal do Rio Grande do Sul. Porto Alegre, 2015. Disponível em <https://www.lume.ufrgs.br/bitstream/handle/10183/140274/000990758.pdf?sequence=1>. Acesso em 12 out 2019.

ONEDA, Luana Lays; PERIN, Mariana; THIVES, Fabiana. A influência da maquiagem na imagem pessoal. 2008. Disponível em < http://siaibib01.univali.br/pdf/Luana\%20Lays\%20Oneda\%20e\%20Mariana\%20Perin.pdf>. Acesso em 13 out 2019.

PEREIRA, Juliana Nunes. Mulheres e empreendedorismo: MEI como política de combate à informalidade. Anais do Encontro Internacional e Nacional de Política Social, v. 1, n. 1, 2020.

PORTAL MEI. Quantidade, salário do funcionário e contribuição do MEl. 2018. Disponível em < https://www.portalmei.org/mei-pode-ter-empregado/>. Acesso em 09 set 2019.

SAMPIERI, R. H.; COLLADO, C.F.; LUCIO, P. B. Metodologia de Pesquisa. 5. ed. São Paulo: MacGraw-Hill, 2013. SEBRAE. Guia do MEI 2018. São Paulo. 2018. Disponível em <https://bibliotecas.

sebrae.com.br/chronus/ARQUIVOS_CHRONUS/bds/bds.nsf/11ae56b04ba6ce6d4c690f29946c890b/\$File/9865.pdf>. Acesso em 10 set 2019.

SEBRAE. O diferencial do bem-estar no negócio de beleza: Entenda o porquê de o segmento de serviços de beleza sempre buscar entregar não só um serviço impecável, mas também a melhor experiência possível ao cliente. 2018. Disponível em <"http://www.sebrae.com.br/sites/PortalSebrae/ufs/pb/artigos/o-diferencial-do-bem-estarem-negocios-

de\%20beleza,34003ea344900610VgnVCM1000004c00210aRCRD?origem=estadual\&codUf=16"codUf=16>. Acesso em 09 set 2019

SESCAP. Sindicato das Empresas de Serviços Contábeis e das Empresas de Assessoramento, Perícias, Informações e Pesquisas no Estado do Paraná - SESCAP. 2019. Reforma trabalhista completa 3 anos; veja os principais efeitos. Disponível em <https://www.sescap-pr.org.br/noticias/post/reforma-trabalhista-completa-3-anos-veja-os-principaisefeitos $>$. Acesso em 14 de jun 2021.

SILVA, Anna Carolina Aguiar da. Perfil Empreendedor: As Principais Características E os Tipos de um

Empreendedor de Sucesso. Monografia. Faculdade de Tecnologia e Ciências Sociais Aplicadas - FATECS. 2014.

SILVA, Rodrigo Rangel da. O Micro Empreendedor Individual MEI - Uma Abordagem Sobre a Efetividade das Vantagens, Beneficios e Desafios Gerados ao Novo Empreendedor. 2014. Disponível em:

$<$ file:///C:/Users/Aline/Downloads/

Artigo_Rodrigo_Rangel_IMPRIMIR.pdf>. Acesso em 19 jun. 2020.

SILVA, Samara Mendes Araújo; FIALHO, Lia Machado Fiuza; QUEIROZ, Zuleide Fernandes de. Apresentação:

Educação e memórias femininas: interfaces e conexões em contextos históricos ocidentais. Educar em Revista, v. 34, n. 70, p. 9-15, 2018.

SILVA, Amanda Suênya de Brito; GUIMARÃES, Jairo de Carvalho. Empreendedorismo feminino: perfil no segmento da beleza e da estética. Revista da Micro e Pequena Empresa, v. 12, n. 2, p. 53-71, 2018.

SIQUEIRA, João Paulo Lara de.; ROCHA, Joyce Silva Leal da; TELLES, Renato. Microempreendedorismo: formalidade ou informalidade? XVI SEMEAD - Seminários em Administração. 2013. Disponível em < http://sistema.semead.com.br/16semead/resultado/trabalhosPDF/423.pdf>. Acesso em 14 jul 2020. 
VALE, Gláucia Maria Vasconcellos; CORREAA, Victor Silva; REIS, Renato Francisco dos. RAC, v. 18, n. 3, art. 4, p. 311327, Maio/Jun. 2014.

VASCONCELOS, Kelly Samá Lopes de. De empresário individual informal a microempreendedor individual (MEI): uma análise dos benefícios da política de formalização. 2016. 64 p. Dissertação de mestrado (Mestrado em Economia) - Departamento de Economia. Universidade Federal de Pernambuco Centro Acadêmico do Agreste, Caruaru, PE.

VERGARA, Sylvia Constant. Projetos e relatórios de pesquisa em administração. 3. ed. São Paulo: Atlas, 2000.

Vergara, Sylvia Constant. Métodos de pesquisa em administração. 5. ed. São Paulo: Atlas, 2012.

YANNOULAS, Silvia Cristina (Coord.). Trabalhadoras: análise da feminização das profissões e ocupações. Brasília: Editorial Abaré, 2013. 304 p. Disponível em:

<http://tedis.unb.br/images/pdf/YannoulasLivroTrabalhadorasFinalCompleto.pdf>. Acesso em: 01 set. 2020.

XAVIER, Almiro Luna et al. História Local e identidade: educação patrimonial e cidadania a partir da comunidade de Anna Florência, Ponte Nova (MG). 2018. Tese de Doutorado. Universidade Federal de Viçosa. 
